\title{
POLÍTICAS PÚBLICAS DE DESENVOLVIMENTO TERRITORIAL RURAL EM GOIÁS
}

Edson Batista da Silva ${ }^{1}$

\section{Resumo}

Este artigo analisa políticas públicas de desenvolvimento territorial rural em Goiás, especificamente os Projetos de Infraestrutura e Serviços em Territórios Rurais-PROINF e o Programa de Agroindustrialização em Assentamentos da Reforma Agrária-TERRA FORTE. Para isso, foram utilizadas pesquisas bibliográfica e documental. Os dados revelam a distribuição desigual dos projetos, com concentração no Centro e no Sul de Goiás, além de demonstrar o caráter setorial, burocrático, municipalista, de resolução da pobreza rural pelo mercado, e, ao mesmo tempo, expõe a negação de políticas estruturais e do conteúdo do projeto de desenvolvimento territorial rural. Soma-se, a isso, a permanência de subalternidades nas populações do campo, com participação frágil de quilombolas e povos indígenas. Houve idealização dos sujeitos e do espaço material, com adesão acrítica ao projeto de desenvolvimento territorial rural europeu.

Palavras-chave: Políticas públicas. Desenvolvimento Territorial Rural. Territórios Rurais. Territórios da Cidadania.

\section{PUBLIC POLICIES FOR RURAL TERRITORIAL DEVELOPMENT IN GOIÁS}

\begin{abstract}
This article analyzes public policies for rural territorial development in Goiás, specifically the Infrastructure Projects and Services in Rural Territories-PROINF and the Agroindustrialization Program in Settlements of TERRA FORTE-Agrarian Reform. For this, bibliographical research and documentary research were used. The data reveal the unequal distribution of the projects, with a concentration in the Center and South of Goiás. They also demonstrate the sectoral, bureaucratic, municipal character of solving rural poverty through the market. In addition to the negation of structural policies and the content of the rural territorial development project. Added the permanence of subordinates in the rural populations, with fragile participation of Quilombolas, indigenous peoples. There was an idealization of the subjects and material space, with uncritical adhesion to the European rural territorial development project.
\end{abstract}

Keywords: Public policies. Rural Territorial Development. Rural Territories. Territories of Citizenship.

\footnotetext{
${ }^{1}$ Professor da Universidade Estadual de Goiás - UEG, no departamento de Geografia dos Campus Formosa e Cora Coralina. Também é docente do Mestrado Acadêmico de Geografia - PPGEO/UEG, Campus Cora Coralina. Email: edson_bat_silva@hotmail.com.
} 


\section{POLÍTICAS PÚBLICAS DE DESARROLLO TERRITORIAL RURAL EN GOIÁS}

\section{Resumen}

Este artículo analiza las políticas públicas de desarrollo territorial rural en Goiás, específicamente los Proyectos de Infraestructura y Servicios en Territorios Rurales-PROINF y el Programa de Agroindustrialización en Asentamientos de Reforma Agraria-TERRA FORTE. Para eso, fueron utilizadas investigación bibliográfica e investigación documental. Los datos revelan la distribución desigual de los proyectos, con concentración en el Centro y en el Sur de Goiás. También demuestran el carácter sectorial, burocrática, municipalita, de resolución de pobreza rural por el mercado. Además de la negación de políticas estructurales y del contenido del proyecto de desarrollo territorial rural. Añadido la permanencia de subordinaciones en las poblaciones del campo, con la frágil participación de quilombolas y pueblos indígenas. Hubo una idealización de los sujetos y del espacio material, con adhesión acrítica al proyecto europeo de desarrollo territorial rural.

Palabras clave: Políticas públicas. Desarrollo Territorial Rural. Territorios Rurales. Territorios de la Ciudadanía.

\section{INTRODUÇÃO}

Este artigo é resultado do projeto "O Campo Goiano: o avanço do capital e os desafios para o desenvolvimento da agricultura familiar camponesa ”, desenvolvido na Universidade Estadual de Goiás, pelo Programa de Mestrado Acadêmico em Geografia, também se origina do projeto: Abordagem Territorial como Estratégia de Desenvolvimento Sustentável e Igualdade de Renda e Gênero nos territórios Médio Araguaia, Vale do Araguaia e Norte (GO), trabalho que acompanhei de fevereiro de 2016 a abril de 2017, na condição de coordenador do Território Rural Norte goiano.

Na Europa, após 1970, o enfoque setorial do desenvolvimento rural foi substituído pelo prisma territorial, multifuncional (DIAS \& MEDEIROS, 2011). Regiões decadentes, dotadas de patrimônio natural, cultural e propícias ao turismo rural foram objeto de apoio dos Estados nacionais. Os agentes do desenvolvimento tornaram-se os atores locais, aliados a sujeitos localizados nas escalas regional, nacional e internacional. Expressões disso foram o Programa Ligações Entre Ações de Desenvolvimento da Economia Rural-LEADER e LEADER+ desenvolvido na União Europeia e o Zonas de Capacitação e Comunidades Empresariais EZ/EC, implementado nos EUA (SABOURIN, 2015; FILHO \& ABRAMOVAY, 2003). Conforme os autores, na América Latina, o desenvolvimento 
territorial rural transformou-se em sinônimo de combate à pobreza e o campo tornou-se espaço de vida, permeado por singularidades e peculiaridades locais.

O debate conceitual resultou na abordagem territorial do desenvolvimento rural. No Brasil essa abordagem, além das referências internacionais, se sustentou na Constituição de 1988, na sua proposição de descentralização da gestão pública, com a criação de inúmeros conselhos, como os Conselhos Regionais de Desenvolvimento-COREDES, os Conselhos Municipais de Desenvolvimento-COMUDES, os consórcios municipais, com experiências importantes de desenvolvimento regional no Sul do Brasil, adicionado a ação da Confederação da Agricultura-CONTAG no Nordeste, especificamente no Projeto Umbuzeiro-Assocene (SABOURIN, 2015; DALLABRIDA, 2010).

Nas primeiras décadas do século XXI, essas experiências e instrumentos legais, o arcabouço teórico/metodológico sustentou a construção das políticas públicas no Brasil e em Goiás, entretanto, a execução dessas políticas considerou todos pressupostos do desenvolvimento territorial rural? Sua efetivação solucionou as desigualdades no campo goiano? O "novo" rural é uma idealização ou uma concretude histórica no estado de Goiás? Diante disso, o objetivo deste texto é analisar algumas políticas públicas de desenvolvimento territorial rural em Goiás. Para isso, recorreu-se à pesquisa bibliográfica, com localização, levantamento, leitura e fichamento de referências. De igual modo, se procedeu à pesquisa documental, com a busca de dados e informações disponíveis para download, no Instituto Nacional de Colonização e Reforma Agrária-INCRA, no Sistema de Gestão EstratégicaSGE, da Secretaria de Desenvolvimento Territorial-SDT, do Ministério do Desenvolvimento Agrário-MDA, que publicou dados do PROINF, disponibilizados pela Coordenadoria de Monitoramento Autorial - CGMA, da Caixa Econômica Federal.

Também foram analisados os Planos de Desenvolvimento Territorial Rural Sustentável-PTDRS e os perfis territoriais dos Territórios Rurais e da Cidadania de Goiás, fornecidos pela SDT. Soma-se a isso, o uso dos dados e informações qualitativas do relatório de atividades realizadas de 2015 a 2017, pelo Núcleo de Extensão em Desenvolvimento Territorial Norte goiano. Os resultados foram apresentados em quadros, tabelas e figuras, assim como no corpo do texto. $\mathrm{O}$ artigo divide-se em duas seções; na primeira, se discutem os conceitos de desenvolvimento territorial rural e políticas públicas, na segunda, se analisam políticas públicas de desenvolvimento territorial rural no estado de Goiás.

\section{DESENVOLVIMENTO TERRITORIAL RURAL E POLÍTICAS PÚBLICAS}


Sabourin (2015) compreende política pública como um conjunto de ações ou inércia que agentes públicos adotam para solucionar problemas determinados. Trata-se de construções provenientes de enfrentamentos das classes e expressam valores, crenças, saberes, princípios, normas, regras sociais. As efetuadas no campo brasileiro na primeira década desse século originam-se de disputas de classe e de determinada concepção de desenvolvimento territorial.

Conforme ressalta Souza (1995), há um imbricamento de território e desenvolvimento, visto que a divisão do poder incide sobre a justiça social. $O$ desenvolvimento como sinônimo de crescimento, de identificação de grupos alvo para aplicação de programas de redistribuição, revela-se distante das necessidades humanas. Concebê-lo como exercício da liberdade, da participação, sem ter em conta o capitalismo, eivado de contradições, de poder heterônomo, significa demagogia política ou proposição de melhorias cosméticas.

O desenvolvimento é o exercício do poder de decidir, autonomia enquanto capacidade de se autorreger, com instituição de mais liberdade e justiça (SOUZA, 1995). Negação do poder do Estado, ceticismo do produtivismo, da modernidade capitalista, controle e gestão do espaço vivido são elementos que compõem essa proposição autonomista. Kay (2018) afirma que, na América Latina, os projetos hegemônicos utilizaram pressupostos estruturalistas, marxistas, neoliberais e neoestruturalistas. A reforma do capitalismo, a adoção do socialismo, o desmonte do Estado desenvolvimentista e seu projeto de substituição de importações foram soluções dadas para superação do desenvolvimento dependente, bem como o equilíbrio do desenvolvimento interno conectado ao mercado global.

Sucintamente, os neoliberais propuseram o desenvolvimento como sinônimo de liberalização, de prioridade do mercado; os neoestruturalistas adotam a combinação e o equilíbrio entre Estado e mercado, os estruturalistas veem o Estado como agente de planejamento, de intervenção e de investimento econômico (KRISTOBAL, 1993). Os neoestruturalistas defenderam o Estado hábil, pragmático, capaz de dirigir o mercado, de investir mirando as exportações e de estimular a promoção da equidade (KAY, 2018).

Mas o progressismo negligenciou os conflitos de classe e sustentou o extrativismo, dando limites e concessões aos capitalistas para comporem seus projetos de desenvolvimento (GUDYNAS, 2019). Sob o slogan "Eu te contamino, mas eu te pago", esses projetos 
ampliaram contradições e limites da exploração da natureza e do trabalho. A crise de exportação de commodities, com redução de preços e declínio da demanda chinesa esgotou o progressismo. O que se vê, no Brasil, é um declínio das políticas de redução da pobreza e de promoção do consumo. Nesse momento, permanece o modelo neoliberal, despido do equilíbrio entre concessões ao mercado e políticas redistributivas.

O desenvolvimento territorial rural das primeiras décadas do século XXI decorre do progressismo, preocupado com a mitigação dos efeitos do neoliberalismo, especificamente com a redução da pobreza rural. Favareto (2010) defende que em 1950 o desenvolvimento rural foi sinônimo de unidade da população com os governos para o desenvolvimento do campo. Entre 1960 e 1980, os programas de desenvolvimento rural foram suprimidos, ressurgiram em 1990, dentro da crise da dívida externa dos países periféricos e das políticas de ajuste estrutural. O Banco Mundial-BM e a Organização para Cooperação e o Desenvolvimento Econômico-OCDE aderiram ao prisma territorial (FAVARETO, 2010; GERALDI, 2012).

Nos países periféricos, esse modelo tornou-se solução para a pobreza rural e para diversificação das exportações (FAVARETO, 2010; FIALHO; WAQUIL, 2008), como é o caso do Brasil, que assimilou os pressupostos teóricos europeus (SCHNEIDER, 2004). Na literatura tornou-se sinônimo de pluriatividade, sustentabilidade e supressão do produtivismo agropecuário, cujas concepções marginais propuseram a superação do agricultor familiar pelo agricultor/camponês, agente de estratégias autônomas. O Brasil aderiu às diretrizes do BM, do Fundo Internacional de Desenvolvimento Agrícola-FIDA, do Instituto Interamericano de Cooperação Agrícola-IICA (SAUBOURIN, 2015; FIALHO, WAQUIL, 2008).

Por isso a literatura nacional assumiu aos termos: pluriatividade, multifuncionalidade, identidade, sustentabilidade, multiescalaridade, conhecimento e empreendedorismo local, capital social, simbólico, descentralização, participação, ativos locais, elementos que conformariam o denominado "novo" rural (ABRAMOVAY, FILHO, 2003; SABOURIN, 2002; SNHEIDER, 2004, CLEMENTE, 2013; DELGADO, LEITE, 2011). Schneider (2004) compreende desenvolvimento territorial rural enquanto processo de transformação produtiva, ambiental e institucional para redução da pobreza e promoção da qualidade de vida. 
Dallabrida (2010) o define como ação social coletiva local organizada, para promoção de mudanças conjunturais e estruturais, condicionadas às determinações macroescalares. A abordagem territorial atende aos objetivos de planejamento e intervenção multiescalar. O território comparece como instrumento normativo e prático, como unidade de planejamento para superação da municipalização das políticas públicas da década de 1990, para criação de novas institucionalidades e para o atendimento das reivindicações dos movimentos sociais e sindicais (ABRAMOVAY, FILHO, 2003; SABOURIN, 2002 \& 2015; SNHEIDER, 2004).

Os Planos Municipais de Desenvolvimento Rural-PMDRs, de 1990, foram construídos como lista de compras, os Conselhos Municipais de Desenvolvimento RuralCMDRs solucionaram questões pontuais (DELGADO, LEITE, 2011). O desenvolvimento rural brasileiro não foi uma proposta autonomista das populações do campo, uma vez que, no seu escopo, o que se defendeu foram arranjos institucionais de integração ao mercado e a municipalização da ação do Estado nacional (GERALDI, 2012). Os pactos e concertações ignoraram disputas de classe, de tal modo que os conflitos foram subestimados (DELGADO, LEITE, 2011, CLEMENTE, 2013).

Os programas redigidos no Ministério do Desenvolvimento Agrário-MDA resultaram em participação decorativa dos camponeses (GERALDI, 2012), haja vista que, nas instâncias territoriais, houve controle de redes e relações sociais dissidentes, estímulo à competição de lugares (municípios), enfim, foi uma panaceia de solução da pobreza via mercado. As políticas ditas de bottom-up, tornaram-se instrumentos de normatização, padronização e disciplinamento dos sujeitos e da realidade, com territorialização de determinadas relações de poder (GERALDI, 2012), ou seja, houve a supressão da questão agrária pelo desenvolvimento.

Fialho \& Waquil (2008), em contraposição, defendem o compromisso do Estado com o desenvolvimento rural. Segundo os autores, os problemas foram decorrentes da desorientação das organizações e da motivação dos agricultores. Favareto (2010), por outro lado, crítica o descompasso entre a concepção e a efetivação desse projeto. Explica que nas instituições territoriais, houve incorporação por adição das dimensões ambiental e territorial, mas permaneceram velhas práticas e valores do enfoque setorial e o lugar subalterno do camponês.

$\mathrm{Na}$ literatura, comparecem outros problemas da efetivação dessa política, tais como: carência de marco legal e capacidade de administração das instâncias territoriais, 
prefeiturização e oposição de governos municipais e estaduais, escassez de tempo, capital político, recursos e legitimidade para fiscalização e participação da sociedade, dependência do poder público municipal, permanência do clientelismo, coronelismo, conservadorismo nas instituições territoriais, privilégio aos agricultores familiares consolidados e precariedade na coordenação e articulação multiescalar (CLEMENTE, 2013; DELGADO, LEITE, 2011; SAUBOURIN, 2015; BONNAL, CAZELLA et. al, 2014; MEDEIROS, MINÁ, 2011).

E a lista de problemas continua, como: a idealização do sujeito histórico do campo brasileiro e a negligência com determinações da política macroeconômica (CLEMENTE, 2013); a associação automática equivocada entre participação popular, descentralização e territorialização do desenvolvimento (SAUBOURIN, 2015); o silêncio sobre a reforma agrária, a regularização fundiária e o crédito fundiário, aspectos estruturais para o desenvolvimento territorial rural (BONNAL, CAZELLA ET. AL, 2014).

Conforme os autores, a superação desses dilemas requeria aprimoramento das instituições territoriais, com profissionalização do gerenciamento, da governança, do suporte técnico, com contratação de profissionais especializados e a dotação de personalidade jurídica dos colegiados territoriais (DELGADO, LEITE, 2011; ABRAMOVAY, FILHO, 2003; BONNAL, CAZELLA ET. AL, 2014). É necessário que haja a devida supressão de concepções anacrônicas do rural, que fortalecem o agronegócio em detrimento da agricultura familiar (MEDEIROS, MINÁ, 2011). As disputas de concepções se associam à consideração das representações mentais das comunidades rurais, que envolvem o capital cultural e simbólico.

A solução deve ser buscada dentro de uma série de critérios, como a participação de segmentos subalternizados da agricultura familiar, o fortalecimento do desenvolvimento territorial rural alternativo, centrado nos sujeitos e no ambiente, erigido pela democracia participativa (DALLABRIDA, 2010), e pela realização de políticas estruturais, como a reforma agrária, para o desenvolvimento econômico, social, sustentável do campo (LEITE, 2011; BONNAL, CAZELLA ET. AL, 2014; MEDEIROS, MINÁ, 2011). O desenvolvimento territorial rural atuou desde espaços e sujeitos ideais, o que se quer dizer é que, muitas vezes, foram ignorados os sujeitos de carne e osso do campo brasileiro.

O campo, com suas diferentes carências estruturais foi negligenciado, ou seja, os campesinat(os) foram territorializados em diferentes regiões do Brasil. Isso significa dizer 
que em determinados locais a escassez é de água, em outros, de sementes, adubos, manejos naturais para o controle das "espécies-praga", com vistas a adoção da agroecologia. Noutros, as terras são exíguas, ou os camponeses estão desterrados, enquanto aqueles que têm a terra integram a cadeias produtivas que os vinculam ao mundo e, contraditoriamente, os empobrecem cotidianamente com apropriação da renda da terra.

Nessa situação, não há como discutir desenvolvimento sustentável ignorando as determinações econômicas macroescalares. A isso se somam os habitus distintos das diferentes frações do campesinato brasileiro. Em outras palavras, em determinados segmentos, existem predisposições para a organização política e econômica, noutros, tais disposições precisam ser construídas, visto que suas concepções de infrapoder endossam relações coronelistas, clientelistas, conservadoras.

Mas os sem-terra, sem água, sem sementes, sem crédito, sem direito à educação, sem participação política, "num passe de mágica", foram responsabilizados pelo desenvolvimento, obrigados a se converterem em empresários rurais eficientes. Houve a absolvição do Estado com relação às disputas de classe, que, ou se omitiu, ou dissimulou os enfrentamentos dos projetos políticos em jogo. O empreendedorismo converteu o território em ator, para negociação das singularidades e particularidades locais. As instituições territoriais serviram a promoção de um nível ótimo de organização, tendo em vista a inserção acrítica no mercado.

Os problemas estruturais do campo brasileiro se tornaram questões de concepção, gestão, legalidade, concertação e adequação das políticas públicas. Faz-se as seguintes indagações: A adesão ao desenvolvimento territorial rural do BM melhorou a distribuição de renda, reduziu a pobreza rural, aplicou os termos conceituais defendidos, reduziu as disparidades regionais no campo em Goiás? De outro modo, representou a identificação de grupos alvos para efetivação de melhorias cosméticas, distantes do desenvolvimento autônomo do campo? Questões que são objeto de preocupação do próximo item.

\section{POLÍTICAS PÚBLICAS DE DESENVOLVIMENTO TERRITORIAL EM GOIÁS}

A política de desenvolvimento territorial em Goiás foi a expressão do projeto político do Partido dos Trabalhadores-PT. Nele, houve a adoção da política da conciliação e do 
silêncio (FORIGO, LERRER, 2019), o que promoveu a reprodução do monopólio fundiário, a criação de políticas redistributivas para a agricultura familiar e internacionalização de corporações nacionais atuantes no agronegócio, com financiamento do Banco Nacional de Desenvolvimento Econômico Social-BNDES.

Em 2003 foi criada no Ministério de Desenvolvimento agrário (MDA) a Secretaria de Desenvolvimento Territorial-SDT, responsável pelo desenvolvimento do Programa Nacional de Desenvolvimento Sustentável de Territórios Rurais-PRONAT. Sua operacionalização e acompanhamento ocorreu por meio da Comissão de Implantação de Ações Territoriais-CIAT, substituída em 2005 pelas Células de Acompanhamento e Informação-CIAT, preteridas em 2009 pelos Núcleos de Extensão e Desenvolvimento Territorial-NEDET (SILVA, 2019).

Os Territórios Rurais e os Territórios da Cidadania consubstanciaram as ações do PRONAT, com o intuito de construir um governo territorial intermunicipal, com criação de institucionalidades para efetivação de intervenções planejadas, participativas, articuladas entre agentes públicos e privados (GERALDI, 2012). A matriz das ações e o PTDRS foram os instrumentos principais do planejamento territorial, aonde foram previstos os projetos específicos prioritários e as ações de monitoramento e avaliação das políticas públicas.

As gestões foram direcionadas pelos Comitê de Gestão Nacional e Comitê de Articulação Estratégica (DELGADO, LEITE, 2011). Os colegiados territoriais foram concebidos como espaços públicos de diálogo, gestão, controle, destinação e tomada de decisões de políticas públicas. Sua composição foi condensada na plenária, no núcleo diretivo e no núcleo técnico. O objetivo dos Territórios Rurais e da Cidadania foi superar a centralização política, econômica e financeira do governo federal, com concentração das ações via projetos territoriais (DALLABRIDA, 2010). A proposta era, também, reduzir a pobreza, garantir renda e trabalho mediante a universalização de programas de cidadania e inclusão produtiva (BONNAL; CAZELLA ET. AL, 2014). O mapa 1 apresenta os Territórios Rurais e da Cidadania criados em Goiás, com os projetos do PROINF desenvolvidos de 2003 a 2015. 


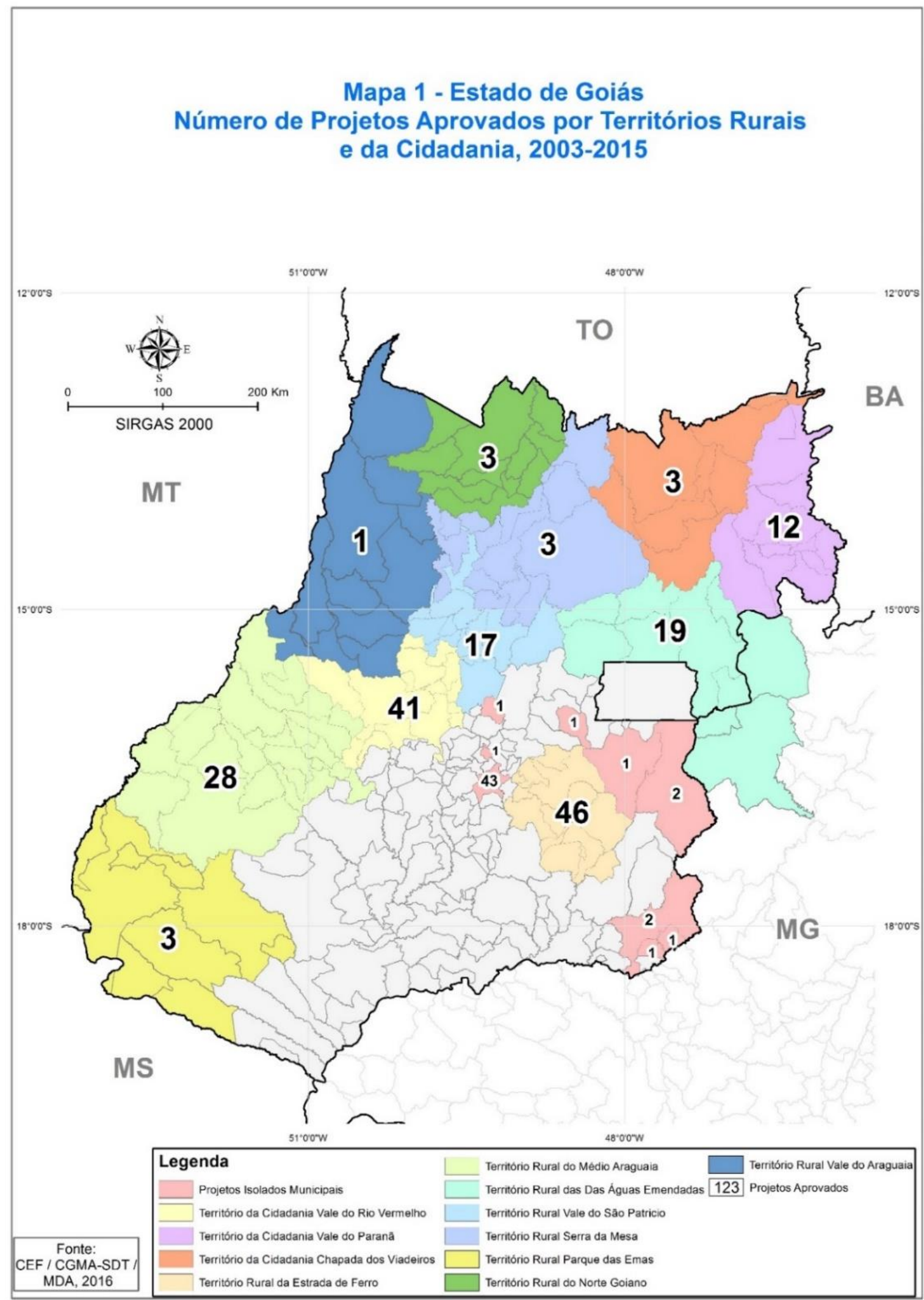


Nota-se a distribuição desigual desses projetos, com concentração nos Territórios Rurais do Médio Araguaia, da Estrada de Ferro, do Vale do São Patrício e das Águas Emendadas, esse último inclui os municípios mineiros de Buritis, Cabeceira Grande e Unaí. De 2003 a 2015, a quantia de $\mathrm{R} \$$ 5.271.736,62 foi destinada ao Território Rural da Estrada de Ferro, R \$ 4.178.297,95 ao Território da Cidadania Vão do Paranã, R \$ 4.043.744,84 ao Território Rural Vale do São Patrício, R \$ 2.334.036,98 ao Território da Cidadania Vale do Rio do Vermelho, R \$2.066.608,60 ao Território Rural do Médio Araguaia, R \$ 1.687.659,38 ao Território Rural das Águas Emendadas, R\$ 698.486,55 ao Território Rural Parque das Emas, $\mathrm{R} \$ 575.211,11$ ao território Rural Norte goiano, $\mathrm{R} \$ 418.670,30$ ao Território Rural Serra da Mesa e R\$253.831,68 ao Território da Cidadania Chapada dos Veadeiros.

Outros R\$ 17.024.142,79 foram destinados a diferentes municípios goianos. O Território Rural das Águas Emendadas possui PTDRS elaborado pelo Instituto Terra BrasilITB. No plano, além da caracterização, estão detalhados os problemas, as oportunidades, os projetos prioritários, com definição das estratégias adotadas para o desenvolvimento do território (MDA, 2006). O Território Rural da Estrada de Ferro também detém PTDRS formulado, onde consta a caracterização e a indicação de redação de políticas públicas prioritárias para a valorização dos jovens e das mulheres, de efetivação da educação do campo, da assistência técnica pública e comunitária, de avanços na infraestrutura, na conservação ambiental e na qualidade de vida (MDA, 2010).

Nesse território, elege-se a produção leiteira como a atividade hegemônica, o que impõe prioridade ao fortalecimento da cadeia produtiva do leite, em atenção às suas debilidades e resistências. Esse PTDRS possui uma matriz em que consta prioridade de elaboração de projetos nas seguintes áreas: educacional, sociocultural, ambiental e de desenvolvimento de atividades produtivas. O Território Rural Vale do São Patrício detém somente um perfil territorial apresentado (MDA, 2015), enquanto o Território Rural do Médio Araguaia possui o PTDRS.

Nesse documento, estão identificados os eixos estratégicos de ação, com a consecução dos objetivos e estratégias fundamentais aprovadas nas dimensões sociocultural e de infraestrutura, com vistas a fortalecer cadeias produtivas, por exemplo, da apicultura e da produção leiteira (MDA, 2006). No mapa 1, também se observa concentração de projetos do PROINF nos Territórios da Cidadania Vale do Rio Vermelho e no Vale do Paranã. Na pesquisa documental, constatou-se apenas documentos de caracterização desses territórios. 
No mapa apresentado, os territórios rurais do Parque das Emas, Serra da Mesa e Norte Goiano possuem diminutos projetos realizados. Na pesquisa, não se identificou PTDRS elaborado desses territórios.

O Território da Cidadania Chapada dos Veadeiros e o Território Rural Vale do Araguaia também realizaram poucos projetos do PROINF, ambos detêm somente perfis territoriais redigidos. No mapa supracitado se percebem projetos municipais isolados do PROINF, com destaque para o município de Goiânia, com quarenta e três propostas desenvolvidas. Na execução do projeto Abordagem Territorial como Estratégia de Desenvolvimento Sustentável e Igualdade de Renda e Gênero nos territórios Médio Araguaia, Vale do Araguaia e Norte (GO), na condição de coordenador do Território Rural Norte goiano, pude constatar o estágio de "gestação" desse território.

Nos contatos iniciais, em julho de 2015, foram identificados apenas coordenadores provisórios, eleitos para o colegiado territorial em 2009, que representavam quatro dos onze municípios integrantes do território. No diagnóstico, foi relatada a inexistência de institucionalidades territoriais, (comitê diretivo, núcleo técnico e câmaras temáticas), com dificuldades de realização de plenárias, por exemplo, para participação em chamadas de políticas públicas. O NEDET Norte e os coordenadores provisórios promoveram, em novembro de 2015, plenária extraordinária territorial, momento em que cinco novos representantes se somaram à comissão existente.

Os membros do poder público, da sociedade civil e o NEDET decidiram promover ações para garantir a instituição do território. O coordenador, acompanhado do Assistente de Inclusão Produtiva-ATIP e do Assistente de Gestão Social-ATGS, mediante agenda previamente elaborada, realizaram visitas entre novembro de 2015 e março de 2016 em associações de camponeses assentados, proprietários e beneficiários do crédito fundiário. Essa ação também foi empreendida em cooperativas, Sindicatos de Trabalhadores e Trabalhadoras Rurais-STTRs e autarquias do Estado.

A mobilização e o trabalho de base instituíram sete CMDRs provisórios em municípios que tinham leis de criação dessas institucionalidades e reestruturou o conselho do município de Porangatu. Também foram escolhidos representantes da sociedade civil e do poder público para a eleição do comitê diretivo, da câmara técnica e das câmaras temáticas de mulheres, juventude e comercialização realizada na plenária territorial de abril de 2016. Na revisão do regimento de funcionamento do território, ficou pactuado que os CMDRs indicariam os representantes municipais para o colegiado territorial. De abril a 
dezembro de 2016, foram traçados planos de formação, capacitação e planejamento do PTDRS, os quais foram executados com o núcleo diretivo, a câmara técnica e as câmaras temáticas recém constituídas do Território Rural Norte.

Atividade similar desenvolvida com os conselheiros dos CMDRs provisórios, com redação de planos de ação para o desenvolvimento territorial local. No quadro 1, notam-se outras ações promovidas pelo NEDET no Território Rural Norte goiano. Essas atividades de formação, capacitação e planejamento ocorreram após a constatação de coleta, comercialização in natura, ou beneficiamento artesanal de frutas típicas do Cerrado. Todavia, outros problemas surgiram, como o uso de máquinas do Programa de Aceleração do Crescimento-PC2, destinadas prioritariamente à agricultura familiar, mas utilizadas nos centros urbanos, ou apropriadas pela oligarquia agrária local para reforma de estradas vicinais, construção de represas e transporte de calcário para seus latifúndios. Houve diminuta inserção dos camponeses no Programa de Aquisição de Alimentos-PAA e no Programa Nacional de Alimentação Escolar-PNAE.

O argumento dos agentes públicos foi que os camponeses não desenvolviam atividades produtivas. Mas o que se sabe é que tais razões envolviam clientelismo, coronelismo, acordos políticos locais e frágil organização política e econômica dos camponeses. Naquele território, constatou-se cinco cooperativas, mas somente três em funcionamento: Cooperativa dos Produtores de Açafrão de Mara Rosa COOPERAÇAFRÃO, Cooperativa de Apicultores e Agricultores Familiares do Norte Goiano - COOPERMEL (Porangatu), Cooperativa Mista Agropecuária dos Agricultores Familiares de Formoso - COOPERFOR, especializadas na comercialização de açafrão, mel e leite, respectivamente.

Os camponeses, sobretudo os assentados, tinham dificuldade de acesso a Declaração Jurídica de Aptidão ao Programa Nacional de Fortalecimento da Agricultura Familiar-DAP. Os grupos informais, as inserções individuais, com possível concorrência de organizações econômicas formais, conformavam instrumentos político-econômicos frágeis. A débil política de Assistência Técnica e Extensão Rural-ATER, também comprometia a inserção no PAA, no PNAE e o acesso ao Programa Nacional de Fortalecimento da Agricultura FamiliarPRONAF.

Quadro 1 - Estado de Goiás - Território Rural Norte Goiano - Ações de gestão social e 
inclusão produtiva, 2015 a 2017.

\begin{tabular}{|c|c|c|}
\hline Instituição promotora & Ação desenvolvida & Objetivo proposto \\
\hline NEDET/ EMBRAPA & $\begin{array}{l}\text { Unidades de construção do } \\
\text { conhecimento. }\end{array}$ & \begin{tabular}{|ll} 
Difundir & práticas \\
agroecológicas. & \\
\end{tabular} \\
\hline NEDET & $\begin{array}{l}\text { Visita a Feira da Agricultura } \\
\text { Familiar de Goianésia. }\end{array}$ & $\begin{array}{ll}\begin{array}{l}\text { Formação } \\
\text { camponeses/feirantes. }\end{array} \\
\end{array}$ \\
\hline EMATER & $\begin{array}{l}\text { Cursos de beneficiamento } \\
\text { do Pequi. }\end{array}$ & $\begin{array}{l}\text { Beneficiamento de frutos } \\
\text { do Cerrado. }\end{array}$ \\
\hline EMATER/NEDET & $\begin{array}{l}\text { Seminário sobre Programa } \\
\text { de Garantia de Preço } \\
\text { Mínimo da Biodiversidade } \\
\text { (PGPM-Bio). }\end{array}$ & $\begin{array}{l}\text { Capacitação para o } \\
\text { acesso a política pública } \\
\text { do PGMBio. }\end{array}$ \\
\hline $\begin{array}{l}\text { NEDET- CAMPONESES } \\
\text { AGROECOLÓGICOS }\end{array}$ & $\begin{array}{l}\text { Intercambio: Curso prático } \\
\text { de Sistemas Agroflorestais. }\end{array}$ & $\begin{array}{l}\text { Difusão de práticas } \\
\text { agroecológicas. }\end{array}$ \\
\hline $\begin{array}{l}\text { NEDET/FIC/UFG } \\
\text { (MAGNIFICA MUNDI) }\end{array}$ & $\begin{array}{l}\text { Oficina de Comunicação } \\
\text { Popular. }\end{array}$ & $\begin{array}{l}\text { Disseminar experiências } \\
\text { de mídia comunitária. }\end{array}$ \\
\hline NEDET & $\begin{array}{l}\text { I Seminário de Jovens do } \\
\text { Território Norte. }\end{array}$ & $\begin{array}{lll}\text { Capacitação } & \text { para o } \\
\text { acesso em } & \text { políticas } \\
\text { públicas. } & & \\
\end{array}$ \\
\hline $\begin{array}{l}\text { FETAEG, CECAF, DFDA, } \\
\text { NEDET }\end{array}$ & $\begin{array}{l}\text { I Seminário de Políticas } \\
\text { Públicas e Comercialização } \\
\text { Institucional, (PNAE } \\
\text { PAA). }\end{array}$ & 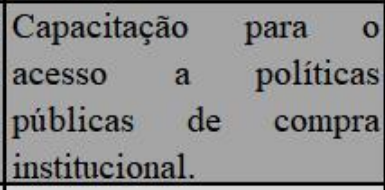 \\
\hline $\begin{array}{l}\text { GEMES/SEDUCE, DFDA, } \\
\text { NEDET }\end{array}$ & $\begin{array}{l}\text { Seminário de } \\
\text { Comercialização } \\
\text { institucional pelo Programa } \\
\text { Nacional de Alimentação } \\
\text { Escolar-PNAE. }\end{array}$ & 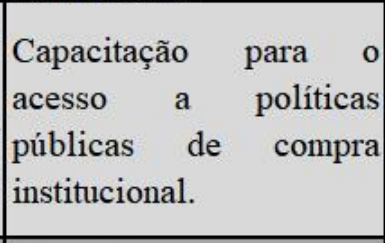 \\
\hline $\begin{array}{l}\text { GEMES/SEDUCE, DFDA, } \\
\text { NEDET }\end{array}$ & $\begin{array}{l}\text { II } \quad \text { Seminário } \\
\text { comercialização } \\
\text { Institucional, PNAE. }\end{array}$ & $\begin{array}{l}\text { Capacitação para o } \\
\text { acesso a políticas } \\
\text { públicas de compra }\end{array}$ \\
\hline $\begin{array}{l}\text { NEDET, } \quad \text { FIC/UFG } \\
\text { (MAGNIFICA MUNDI) }\end{array}$ & $\begin{array}{l}\text { I } \quad \text { Seminário } \\
\text { Comunicação Popular. }\end{array}$ & $\begin{array}{l}\text { Disseminar experiências } \\
\text { de mídia comunitária. }\end{array}$ \\
\hline EMATER/NEDET & $\begin{array}{l}\text { curso de beneficiamento de } \\
\text { alimentos: pequi, hortaliças } \\
\text { e pimenta. }\end{array}$ & $\begin{array}{l}\text { Capacitação } \\
\text { beneficiamento } \\
\text { alimentos. }\end{array}$ \\
\hline
\end{tabular}

Fonte: Relatório do Território Rural Norte, $2017 \quad$ Elaboração: Autor

Isso se somava à exígua quantidade de agências do Banco do Brasil e a alta rotatividade dos funcionários operadores do programa. Tornou-se recorrente depoimentos de camponeses assentados que aguardavam oito, dez anos pelo acesso ao PRONAF. Outras motivações das ações apresentadas no quadro 1 foram o fortalecimento de cadeias produtivas, além da difusão de práticas de comercialização direta, com ações de mobilização, articulação, orientação, por exemplo, para construção da Feira de Agricultura Familiar Camponesa do Município de Mutunópolis. 
A proposição de mercados alternativos foi disseminada nos CMDRs. Nos municípios de Porangatu e Novo Planalto, os camponeses se articularam para a efetivação de Feiras da Agricultura Familiar. Trombas retomou essa ação de comercialização direta. A articulação do CMDRs com o poder público municipal culminou no cartão verde, emitido pela Secretaria Municipal de Assistência Social no valor R\$20,00, destinado exclusivamente à aquisição de alimentos. Os diferentes níveis de institucionalização e organização dos Territórios Rurais e da Cidadania expressam o espaço desigual, contraditório e combinado no campo goiano. Determinados territórios careciam de mobilização, articulação, trabalho de base para sua efetivação.

Noutros já instituídos, o planejamento, a coordenação e a gestão se deram para obtenção de políticas públicas. A abordagem territorial, de certo modo, também esvaziou experiências anteriores, como os CMDRs, importante instrumento construído na década de 1990. No estado de Goiás, a distribuição desigual do PROINF é coetânea ao nível de institucionalização dos territórios Rurais e da Cidadania. A política territorial efetuada revelou questões observadas pela literatura nacional em Territórios Rurais e da cidadania no Brasil, como é o caso dos territórios que requeriam mobilização e formação, dado o número reduzido de lideranças e proposta de desenvolvimento territorial rural redigida (ABRAMOVAY, FILHO, 2003).

Frações do campesinato (assentados), foram considerados exóticos às forças sociais e ao poder público municipal, com isso, foram tratados como problemas do governo federal. $\mathrm{Na}$ execução de tais projetos sociais, viu-se que os problemas se acumulam, tais como: reduzido número de profissionais de planejamento nos municípios, somado à diminuta tradição de planejamento intermunicipal (BONNAL, CAZELLA ET. AL, 2014); aumento das desigualdades regionais, sobretudo de acesso a projetos de infraestrutura e serviços, com apoio aos camponeses consolidados (CLEMENTE, 2013); contradição entre governo territorial e dependência do poder municipal, sobretudo para proposição de projetos do PROINF (GERALDI, 2012; SAUBOURIN, 2015).

E a lista continua: a participação dos camponeses fica condicionada aos recursos financeiros, pela exígua cultura democrática, pelas concepções de infrapoder. No NEDETNORTE, a formação do território privilegiou a organização de classe, articulada pelos movimentos sociais; houve a promoção de mercados e processos de agroindustrialização alternativos; a apropriação das políticas públicas; a atenção às subalternidades no interior do 
campesinato e a difusão da agroecologia. A tabela 1 demonstra as características dos projetos do PROINF desenvolvidos em Goiás.

Os dados revelam tendência de especialização do campesinato na produção leiteira, com tecnificação do armazenamento, da reprodução e da alimentação do rebanho bovino. No setor avícola, houve dotação de equipamentos, sobretudo para o abate de aves. O pacto tecnológico adotado foi proveniente da "Revolução Verde", especificamente das corporações multinacionais atuantes no agronegócio. Na tabela 1, do mesmo modo, são demonstrados projetos de infraestrutura para eliminação dos intermediários, dotação de espaços para comercialização direta, importantes mecanismos para apropriação da renda da terra, além da provisão de infraestrutura de produção, agroindustrialização e comercialização apícola.

Outros projetos disponibilizaram aos camponeses equipamentos, serviços e insumos para produção agrícola, correção do solo, beneficiamento e transporte da produção agropecuária e informatização das atividades produtivas. Em contrapartida, houve poucas propostas de produção agroecológica, educação do campo e conservação do Cerrado. Os projetos também apoiaram a construção dos Territórios Rurais e da Cidadania, os CMDRs e proporcionaram cursos para formação de organizações políticas, econômicas, dentre outros fins de gestão social e desenvolvimento produtivo.

$\mathrm{Na}$ tabela 2, estão demonstradas as intromissões das prefeituras nos projetos, bem como o controle da redação e submissão por autarquias públicas do estado de Goiás, empresas de Assistência Técnica e Extensão Rural, com reduzido número de propostas realizadas por movimentos sociais, associações, cooperativas e STTRs. No ano de 2016, do montante de projetos do PROINF submetidos entre 2003 e 2015, 87\% estavam concluídos, $6 \%$ tinham obras paralisadas, 6\% não iniciadas e 1\% atrasadas. De 2003 a 2006 foram desenvolvidos 51,29\% dos projetos, de 2007 a 2010, 34,91\%, de 2011 a 2015, 13,79\%. No Território Rural Norte, a redução orçamentaria das políticas públicas após 2010 dificultou a atuação do NEDET Norte, em decorrência das promessas não cumpridas das autarquias do Estado. No município de Montividiu do Norte, a Cooperativa de Montividiu do NorteCOOPERMU submeteu projeto de construção de frigorífico em chamada pública do Terra Sol. 


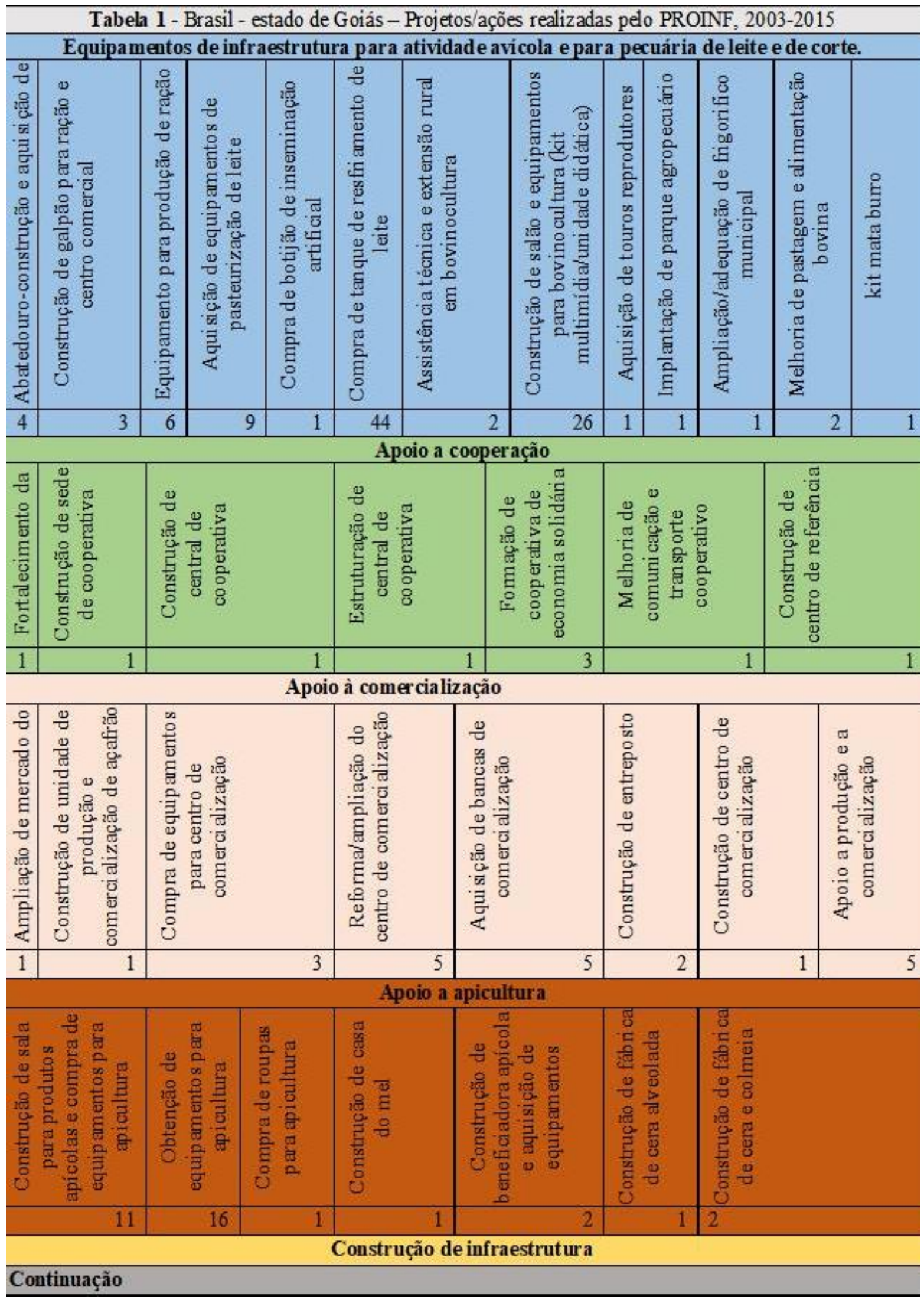


Políticas públicas de desenvolvimento territorial rural em Goiás

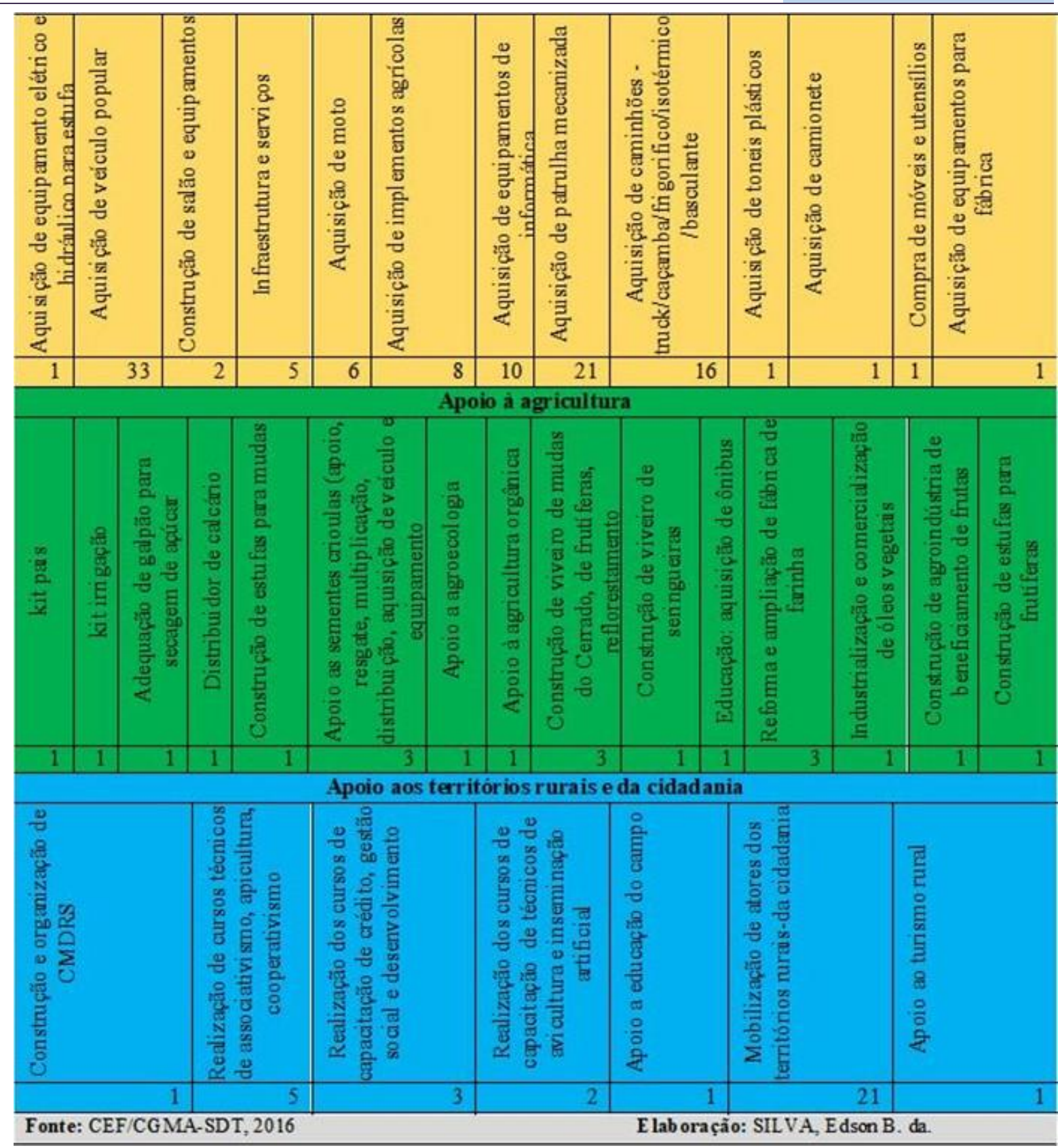

Tabela 2 - estado de Goiás - Atores proponentes de projetos do PROINF, 2003-2015.

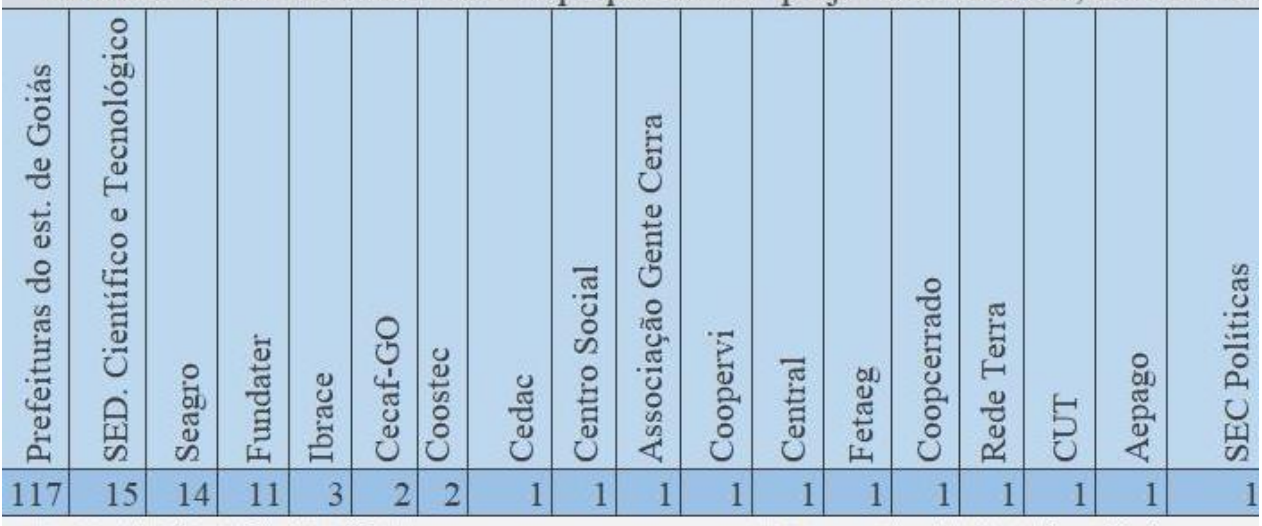

Fonte: CEF/CGMA-SDT, 2016

Elaboração: SILVA, Edson B. da 
O INCRA se comprometeu a instalar a estrutura, mas a não efetivação dessa agroindústria provocou tensões internas na cooperativa. As famílias assentadas foram compelidas a entregar sua produção ao PAA. O NEDET Norte constatou que o território obteve dois projetos no valor de $\mathrm{R} \$ 575.211,11$. No ano de 2010 a prefeitura de Mara Rosa, município sede da COOPERAÇAFRÃO, submeteu projeto para construção de uma unidade de processamento e comercialização de açafrão, no valor de $\mathrm{R}$ \$ 207.639,17.

No mesmo município, foi submetido e aprovado em 2011 outro projeto de aquisição de veículo para transporte de açafrão, orçado em R $\$ 367.571,94$. No ano de 2015 foi reprovado o projeto da COOPERMEL, para aquisição de veículo para o transporte de mel. A prefeitura municipal de Porangatu não comunicou à cooperativa e à câmara técnica do território necessidades de correção da proposta. Esses aspectos somados à reduzida obtenção de outras políticas públicas resultaram em comportamentos constatados por Bonnal, Cazella et. al (2014) para outros territórios no Brasil.

Os camponeses, diante da paralisação das políticas públicas, entenderam como "tempo perdido" participar do colegiado territorial, o que culminou em desmobilização e desmotivação. Medeiros, Miná (2011) acrescentam que isso expôs outras fragilidades, tais como: territórios construídos para transferir dinheiro, colegiados territoriais que não promoveram reflexão, acordos para solução de problemas, com imposição de demandas políticas nas diferentes esferas do Estado. Isso os transformou em espaços de implementação de políticas públicas, em detrimento de territórios de vida e identidade. Quanto ao Programa de Agroindustrialização em Assentamentos da Reforma Agrária- TERRA FORTE, do montante de três milhões de reais destinados em 2014 para o Brasil, foram selecionados cinco projetos para o Centro-Oeste.

O estado de Goiás recebeu um projeto, cuja organização contemplada foi a Associação dos Pequenos Produtores Rurais da Agricultura Familiar do Vale do AraguaiaASPRAFAVA, localizada em Bom Jardim de Goiás, com extensão em Mato Grosso do Sul e Mato Grosso. De modo geral, os projetos do PROINF em Goiás revelaram situações que foram constatadas na literatura nacional sobre a política de Desenvolvimento Territorial Rural no Brasil. A despeito da constituição de espaços de participação, planejamento, avaliação, acesso à informação, dialogo, capacitação (FIALHO, WAQUIL, 2008; DELGADO, LEITE, 2011), os territórios se converteram em regiões-problemas, uma vez que a pobreza se tornou um empecilho ao desenvolvimento do mercado (GERALDI, 2012). 
Os projetos tiveram recorte setorial, sem apoio à diversificação produtiva, valorização dos modos de vida, também abandonaram políticas estruturais (BONNAL, CAZELLA ET. AL, 2014). O PROINF se revelou burocrático, aprisionado ao rigor da Caixa Econômica Federal, submetido às regras do TCU, com desestímulo à atuação do poder público municipal (SAUBOURIN, 2015). Projetos de valorização de bens intangíveis, (patrimônio cultural, histórico, paisagístico), foram exíguos (SCHNEIDER, 2004; FIALHO, WAQUIL, 2008). A política territorial, sobretudo do Territórios da Cidadania assumiram caráter top-down. Sem atingir seus desejados objetivos, o PRONAT foi pouco significativo para a resolução da pobreza rural, distribuição de renda e geração de emprego (SAUBOURIN, 2015).

\section{CONSIDERAÇÕES FINAIS}

A concepção de desenvolvimento territorial rural ignorou os campesinatos. A concepção nacional das políticas públicas, com a devida adequação e enquadramento dos camponeses territorializados no Brasil e em Goiás engendrou a idealização dos sujeitos e do espaço material. O sujeito idealizado, o agricultor familiar, em inúmeros espaços, foi negado pelos sujeitos existentes. O espaço material, com extrema concentração fundiária, com relações de poder coronelista, clientelista, paternalista, e ausência de organizações econômicas camponesas, se revelou distante dos pré-requisitos para instalação da política territorial. O espaço existente pesou nos sucessos do projeto de desenvolvimento territorial capitalista para o campo brasileiro.

Isso não significa que não houve melhorias cosméticas, conjunturais, com redução da pobreza rural, melhorias da distribuição de renda, geração de emprego, por exemplo, por meio das políticas de comercialização, agroindustrialização, educação, saúde, mas os desafios para o desenvolvimento da agricultura familiar permanecem no Brasil e em Goiás.

Não se nega a importância das políticas públicas, por exemplo, de comercialização institucional, de dotação de infraestruturas para os camponeses(as) brasileiros. O que se crítica é a atuação desde espaços e sujeitos idealizados, que promovem desencontros, fracassos na implementação delas. Também é necessário apoiar à reforma agrária, combater o pacote tecnológico da "Revolução Verde", a privatização da água, defender a adoção de políticas efetivas contra o cerco de apropriação da renda da terra. Os camponeses sentem isso cotidianamente, por isso realizam ocupações, acampamentos, manifestações, feiras 
agroecológicas, mercados alternativos. O desenvolvimento territorial é possível desde que promovido pelo campesinato, pelos intelectuais aliados dos movimentos sociais, pela unidade do diverso, que inclui a classe trabalhadora urbana. O campo do agricultor(a) agroecológico(a) é o desafio do desenvolvimento territorial autônomo para a América Latina.

\section{REFERÊNCIAS}

ABRAMOVAY, Ricardo; FILHO, Luís Carlos Beduschi. Desafios para a gestão territorial do desenvolvimento sustentável no Brasil. In: XLI Congresso Brasileiro de Economia e Sociologia Rural (SOBER), 27 a 30 de Jul. de 2003 - Juiz de Fora - MG. p. 1-23.

BONNAL, Philippe; CAZELLA, Ademir Antônio; DELGADO, Nelson Giordano. Et al. Desenvolvimento territorial e políticas de enfrentamento da pobreza rural no Brasil. CAMPO-TERRITÓRIO: revista de geografia agrária, nº 17, v. 9, p. 540-573, abr. 2014

CAIXA ECONÔMICA FEDERAL - COORDENADORIA DE MONITORAMENTO AUTORIAL. PROINF: lista de projetos. Brasília: CEF/CGMA, 2016. s/p.

CLEMENTE, Evandro César. Análise da proposta do desenvolvimento territorial na realidade brasileira. Geoambiente on-line: revista eletrônica do Campus Jataí, nº 21, p. 127$151,2013$.

CRISTOBAL, kaio. Para uma renovação dos estudos de desenvolvimento: Teorias latinoamericanas e neoliberalismo na era da estrutura ajustamento. Third World Quarterly, $\mathrm{n}^{\mathbf{0}} 4$, v. 14 , p. 1-9, 1993.

CONSELHO NACIONAL DE DESENVOLVIMENTO CIENTÍFICO E TECNOLÓGICO. Modalidade do projeto: Multiterritorial: Abordagem territorial como estratégia de desenvolvimento sustentável e igualdade de renda e gênero nos territórios Médio Araguaia, Vale do Araguaia, Norte (GO) (Chamada CNPq/MDA/SPM-PR N ${ }^{\circ}$ 11/2014). Brasília: CNPQ, 2015. 35 p.

DALLABRIDA, Valdir Roque. Desenvolvimento e governança territorial: um ensaio preliminar sobre a necessidade da regulação no processo de gestão do desenvolvimento. REDES, Santa Cruz do Sul, no. 3, v. 15, p. 165-186, set/dez. 2010

DELGADO, Nelson Giordano; LEITE, Sergio Pereira. Políticas de desenvolvimento territorial no meio rural brasileiro: novas institucionalidades e protagonismo dos atores. Dados - Revista de Ciências Sociais, nº 2, v. 54, pp. 431-473, 2011.

DIAS, Marcelo Miná; MEDEIROS, Leonilde Servolo. Introdução. In: LEITE, Sergio Pereira; DELGADO, Nelson Giordano. Políticas Públicas, Atores Sociais e Desenvolvimento Territorial no Brasil. Brasília: IICA, 2011. p. 13-34. 
FAVARETO, Arilson. A abordagem territorial do desenvolvimento rural - mudança institucional ou "inovação por adição"? Estudos avançados, n 68, v 24, p. 299-319, 2010.

FIALHO, Marco Antônio Verardi; WAQUIL, Paulo Dabdab. O desenvolvimento rural: concepções e referências para a proposição de políticas públicas de desenvolvimento nos territórios rurais. Revista Extensão Rural, DEAER/CPGExR - CCR - UFSM, Ano XV, p.129- 165, jan./Jun. de 2008.

FORIGO, Adriano de Almeida; LERRER; Débora. A política de silêncio do problema agrário brasileiro. Estudos Sociedade e Agricultura, no 3, v. 27, p. 1-26, 2019/2020.

GERARDI, Juliano. Análise conceitual da política de Territórios Rurais: o desenvolvimento territorial rural no Brasil. Planejamento e políticas públicas, n. ${ }^{\circ} 39$, p. 155-185, jul./dez. 2012.

GUDYNAS, Eduardo. Extrativismo: tendências e consequências. In: WISE, Delgado Raúl; MUNK, Ronaldo (Ed.). Reformulando o Desenvolvimento Latino-americano. Londres: Routledge, 2018. 16 p.

KAY, Cristobal. As contribuições latino-americanas para a teoria crítica de desenvolvimento. Caderno CRH, Salvador, nº 84, v. 84, p. 451-462, set./dez. 2018.

MINISTÉRIO DO DESENVOLVIMENTO AGRÁRIO. Plano territorial de desenvolvimento rural sustentável do Território Rural do Médio Araguaia. Brasília: MDA/SDT, 2006. Disponível em: http://sit.mda.gov.br/download/ptdrs Acesso em: 27 de jul. de 2020.

Plano territorial de desenvolvimento rural sustentável do Território Rural da Estrada de Ferro. Brasília: MDA/SDT, 2010. 44 p. Disponível em: http://sit.mda.gov.br/download/ptdrs Acesso em: 27 de jul. de 2020.

Plano territorial de desenvolvimento rural sustentável do Território Rural das

Águas Emendadas. Brasília: MDA/SDT, 2006. 122 p. Disponível em: http://sit.mda.gov.br/download/ptdrs Acesso em: 27 de jul. de 2020.

Perfil territorial do Território Rural do Vale do São Patrício. Brasília: MDA/SDT, 2006. 7 p. Disponível em: http://sit.mda.gov.br. Acesso em: 29 de jul. de 2020.

NÚCLEOS DE EXTENSÃO E DESENVOLVIMENTO TERRITORIAL DO TERRITÓRIO RURAL NORTE GOIANO. Relatório das atividades realizadas pelo Núcleo de Extensão em Desenvolvimento Territorial Norte goiano, de 2015 a 2017. Goiânia: não publicado, 2017. 63 p

SABOURIN, Eric Pierre. Desenvolvimento Rural e Abordagem Territorial: conceitos, estratégias e atores. In: TEIXEIRA, Olívio Alberto; SABOURIN, Eric Pierre (edit.). Planejamento e Desenvolvimento dos Territórios Rurais: conceitos, controvérsias e experiências. Brasília: Embrapa Informação Tecnológica, 2002. p. 21-37. 
Evolução da política federal de desenvolvimento territorial no Brasil. Novos Cadernos NAEA, n. 1, v. 18, p. 123-143, jan-jun. 2015.

SILVA, Anderson Antônio. Brasil: compreendendo as políticas públicas de desenvolvimento territorial rural (PDTRS) durante os governos LULA e Dilma Rousseff. In: Congress of the Latin American Studies Association, Boston, USA, 24 a 27 de maio de 2019. p. 1-20.

SCHNEIDER, Sérgio. A abordagem territorial do desenvolvimento rural e suas articulações externas. Sociologias, $n^{\circ}$ 11, p. 88-125, 2004.

SOUZA, Marcelo José Lopes de. O território: sobre espaço e poder, autonomia e desenvolvimento. In: CASTRO, Iná Elias; CORREA, Roberto Lobato et al. (orgs.). Geografia: conceitos e temas. Rio de Janeiro: Bertrand Brasil, 1995. 78-116 p.

Recebido em 13 de agosto de 2020

Aceito em 24 de junho de 2021

Publicado em 30 dezembro de 2021 